\title{
LANGUAGE ASSISTANCE TO MULTINATIONAL PARTNERS IN COALITION OPERATIONS
}

\author{
Kateryna SYNYTSYA and Greta KEREMIDCHIEVA
}

Extended abstract: Knowledge of medical-related terminology and communication skills are essential for multinational partners participating in a wide variety of missions - combat, stabilization, humanitarian support and natural disaster relief. In case of injures and sickness they need to know basic medical terminology in English to evaluate the situation, arrange for MEDEVAC or coordinate health services. Although the First aid and MEDEVAC topics are included into many language training programs, participants are unable to use health-related vocabulary in challenging situations due to the lack of language practice and limited training time.

The purpose of this study was to identify specific needs of the multinational partners in medical terminology, explore a range of technology-enhanced language learning strategies for vocabulary extension and refreshing, and suggest a framework for medical terminology assistance based on mobile learning. The study started with needs analysis to reveal specific language gaps and challenges in use of common medical terminology that may be addressed by individual mobile learning. It was intended to identify typical communication situations and vocabulary that should be addressed. Native and non-native English speakers from 14 NATO and partner countries (officers and civilians) who had participated in stability operations and other missions around the world were interviewed and answered a questionnaire. Additionally, five instructors who teach medical and health-related English to future mission participants were interviewed. As a result, three main areas of vocabulary were identified: parts of body, injuries and other health issues (feelings, symptoms), and medical assets/devices used for first aid and healthcare prescriptions. Most typical communication situations were related to car accidents, MEDEVAC calls, taking a person to the hospital, and writing a report about the accident.

To identify the best way of exploiting mobile learning for language assistance to the multinational partners we focused on clarifying the differences between e-learning and m-learning and identifying specific features of m-learning that may be beneficial and even unique in supporting terminology acquisition for the multinational audience. Early research in m-learning emphasized limitations of the mobile devices, such as size of the display, reduced input, small memory, abridged or specific OS version, and lack of standards, which positioned m-learning as a specific case of e-learning. However, rapid evolution of mobile technologies, their recent features, 
including efficient and reliable tactile display, automated adjustment of the resolution and the like, put m-learning on an equal footing with e-learning. Moreover, as distribution of mobile devices significantly exceeds the number of personal computers, and "digital native" generation uses these devices extensively not only for communication but also for accessing information on the web, mobile access to elearning content may increase several times in the near future.

M-learning is perceived to be more flexible, more personalized, more interactive, and more engaging. Due to smaller portions of content and shorter learning session times, m-learning becomes a natural activity during transfer or waiting periods. Moreover, continuous use of the personal mobile device appeals to personalization of learning content through contextual and learning history relevancy. Integrating learning, communication, information exchange and assistance, mobile device became a natural enhancer/extender of the individuals' capabilities.

Extensive study of the literature on vocabulary learning strategies and their computer-based implementation suggested a range of learning activities useful for vocabulary acquisition. However, not all of them promise to be efficient in this specific case, as they do not address individual difficulties and initial vocabulary, short intervals of time that may be devoted to learning, limited attention to language learning due to other priorities, lack of translation to mother language. Moreover, most of the widely used vocabulary extension activities are reading-based, whereas video and audio samples are not properly tagged for share and reuse in vocabulary refreshing. Game-based and context-driven vocabulary acquisition strategies raise learning motivation but their efficiency compared to memorization-based approach has not been measured. In the final part of the study, requirements to the mobile learning environment for medical terminology support are formulated and examples of language learning activities for mobile devices are described.

Keywords: M-learning, computer-assisted language learning, CALL, vocabulary learning strategies, medical terminology.

\section{Introduction}

Multinational forces today are increasingly deployed in humanitarian assistance and stability operations. Development of shared understanding based on effective communication is a major hurdle in coalition operations. Communication and coordination are considered to be key factors for success. The primary issue of concern in multinational networking tends to be achieving adequate levels of competence in one spoken language. While national language is a major factor in this, it should be recognised that other issues such as the availability of a shared, standardised military and medical-related terminology are also essential:

Clearly, in an alliance or coalition environment, interoperability of technology must be accompanied by interoperability of people, process, and organisation in order that a combined military capability can be achieved. We have labelled these latter aspects 'nontechnical interoperability' (NTI). ${ }^{1}$ 
As warfare has changed significantly in terms of range, accuracy and lethality of modern weapons, sustaining the health of the fighting forces is a critical factor in the success or failure of the mission. Shared English language terminology is a vital link in the continuum of care from the point of injury through the health service support (HSS) system to medical treatment facilities (MTFs).

Knowledge of medical-related terminology and communication skills are equally important for multinational partners in a non-combat environment, such as an international disaster response mission or foreign humanitarian assistance. In case of injuries and sickness it is necessary to know basic medical terminology in English to evaluate the situation, arrange for MEDEVAC or coordinate health services. Although First aid and MEDEVAC topics are included into many language training programs, participants are unable to use health-related vocabulary in challenging situations due to the lack of language practice and limited training time.

Technology-supported language assistance and learning content may be offered to enhance individual knowledge and skills through mobile devices and internet access before and during deployment. The purpose of the study is to identify the specific needs of multinational partners in medical terminology, explore a range of technology-enhanced language learning strategies for vocabulary extension and refreshing, and suggest a framework for medical terminology assistance based on mobile learning.

\section{Computer-assisted language learning}

Technology-enhanced learning is widely used in classroom activities and for selfstudy. It is a natural choice in situations when the target training audience is distributed, has no common schedule for training sessions, or needs individually tailored learning content. Computer-assisted language learning (CALL) offers support for a variety of language learning activities, including readings, comprehension tests, drill and practice exercises for vocabulary and grammar, etc. Emerging technologies, such as multimedia content, internet services, the web, and social networking have been gradually incorporated into language learning activities making them more engaging, raising the quality and efficiency of learning, facilitating memorization and understanding. An example of language learning course offered for self-study is ELTEC English Language Training Enhancement Course publicly available through the PfP Consortium ADL Learning Management System (pfp.ethz.ch).

The next stage in technological innovation for learning was the appearance of a variety of small digital devices capable of storing and delivering some type of learning content to the user. The range of mobile devices covers mobile phones and their recent elaborated models - smartphones, handheld devices, such as PDAs and tablet 
PCs, and specialized devices, such as e-books, MP3-players, game-oriented devices etc. The potential of learning through mobile phones was immediately recognized by the CALL community for two reasons. First, the number of mobile phone users is larger than that of computer users and keeps growing. Second, the phone is a primary device for communication and communication is critical for language learning. However, initial experiments demonstrated that additional research is needed to identify the benefits of mobile devices, evaluate the expenses of content adaptation from elearning to m-learning, and work out learning strategies appropriate for mobile learning.

\section{Benefits and challenges of mobile learning}

During the last decade of intensive research and pilots in mobile learning, the core of the concept remains related to the use of mobile (small, handheld) devices and technologies for them. It is illustrated by a simple definition of C. Quinn: “...elearning through mobile computational devices” back in $2000,{ }^{2}$ further elaborated by J. Traxler as "any educational provision where the sole or dominant technologies are handheld or palmtop devices”3 in 2005 and considered from a practical angle by the Mobile ADL community in 2011 as “...the use of handheld computing devices to provide access to learning content and information resources.”4

The main criteria to include a device in this list initially were the portability of the device, its individual use by the owner, and capability both to acquire learning content or information and reproduce it in some form (text, audio, video). In other words, an emphasis was put on the accessibility of content anywhere and at any time the owner needs it. However, for many researchers connectivity is an equally important feature of a mobile device, so those which are not able to support communication between humans or with learning content through phone calls, SMS, or internet are discarded. With recent expansion of 3G/4G connection, mobile devices supporting these standards may be considered as the way to ensure ubiquitous learning as their portability and autonomous power supply together with the widespread internet coverage enabling access to learning content outside the buildings with plugs and cords. Therefore, a mobile device is sometimes perceived as a gateway between the user real and virtual environments, the world around the user, and the knowledge or information which could be obtained "on the move."

Some researchers focus on the "mobility" of a learner rather than a device. In their view, the mobile technologies' value is in support of learning during changing surroundings and the ability to deliver information about real world objects in current learner's environment. This connection between a separate object and environment around it provides context, which is especially important for language learning. The unique role of context for the implementation of immersive and exploratory learning, 
and the potential of modern devices to facilitate learning linked to the environment and situation a learner is in, is expressed in Gary Woodill's definition of mobile learning as "learning in context." 5

Early research in m-learning emphasized limitations of the mobile devices, such as size of the display, reduced input, small memory, abridged or specific OS version, and lack of standards. The attempts to adapt existing content to small devices demonstrated an importance of a trade-off between efforts spent for arranging mobile access and quality of the delivered content. Automatic conversion of interactive learning content to mobile format generally resulted in the loss of quality, whereas design from scratch for each mobile model was too costly.

However, the rapid evolution of mobile technologies, their recent features, including efficient and reliable tactile display, automated adjustment of the resolution and the like, have put m-learning on an equal footing with e-learning. Moreover, as distribution of mobile devices significantly exceeds the number of personal computers, and "digital native" generation uses these devices extensively not only for communication but also for accessing information on the web, mobile access to e-learning content may increase several times in the near future. So, the prediction of the e-learning future suggests that "the future of learning is mobile."

Table 1 outlines certain facets of technology-enhanced learning and typical features for each case.

M-learning is perceived to be more flexible, more personalized, more interactive, and more engaging. Due to smaller portions of content and shorter learning session times, m-learning becomes a natural activity during transfer or waiting periods. Moreover, continuous use of the personal mobile device appeals to personalization of learning content through contextual and learning history relevancy. Integrating learning, communication, information exchange and assistance, mobile devices have become a natural enhancer/extender of the individual capabilities. In perspective, m-learning may facilitate smooth acquisition of knowledge and skills "with less effort, but also without us being conscious that we are learning,"7 i.e. facilitate life-long learning as part of other activities related to business or leisure.

Considering the potential of m-learning from a pragmatic/practical angle, one has to admit that front-end mobile devices are still not available for everyone, their use for learning is not a common practice, and internet connection could be an issue at some locations. Altogether, this brings attention to the "instructional usability" of devices and certain types of learning content and specific situations in which the benefits of their use outweigh the challenges. 
Table 1. Facets of e-learning and m-learning.

\begin{tabular}{lll}
\hline Facet & e-learning & m-learning \\
\hline Environment & Class, home, office & On the move, ubiquitous \\
& Plug \& cable/WiFi & 3G/4G \\
\hline Educational setting & $\begin{array}{l}\text { Formal: school, university, } \\
\text { professional training, dis- } \\
\text { tance and blended }\end{array}$ & $\begin{array}{l}\text { Informal: life-long learning, } \\
\text { performance support, } \\
\text { blended learning }\end{array}$ \\
\hline Instructional paradigm & $\begin{array}{l}\text { Course-based, simulations, } \\
\text { collaboration } \\
\text { "push" }\end{array}$ & $\begin{array}{l}\text { Immersive, exploratory, } \\
\text { situated learning; games } \\
\text { "pull” }\end{array}$ \\
\hline Interaction & Sync/async (internet) and & As in e-learning + \\
& course-based & SMS/MMS \\
\hline Multimedia & Text, pictures, animations, & Video, audio, text and other \\
& other simulations & Authentic capturing \\
\hline Learning session time & 20-40 min & 5-15 min \\
\hline
\end{tabular}

\section{Needs analysis}

Language assistance framework consists of technology enabling mobile access and learning content. Needs analysis was conducted to reveal specific language gaps and challenges in the use of common medical terminology by the multinational partners that may be addressed by individual mobile learning. It was intended to identify typical communication situations and vocabulary that should be addressed through the learning activities and supporting material. As the goal was not to measure language deficiencies within the selected body of language but rather identify areas that might not be addressed during the language training or require reinforcement based on authentic experience of multinational partners, a qualitative approach was selected.

Several techniques were used to elicit information. Focus groups were identified comprised of course participants in George C. Marshall Center and NATO School with mission experience. The size of each group was 5-8 persons depending on the number of individuals available in one place. Discussions with the focus groups helped us to understand the environment, potential emergency situations and related communication tasks. Based on that, a questionnaire was prepared for other needs analysis interviewees to identify their experience in medical and health-related situations which involve the need for communication in English, experienced or observed 
difficulties in communication, language and medical training before the mission, and attitude to the potential use of mobile devices for language assistance. In total, the questionnaire was distributed to 30 participants from 14 NATO and partner countries, including both officers and civilians, who had participated in various kinds of multinational missions around the world. Some of them decided to take part in the individual interviews to share their experience in more detail. Most of the participants were non-native English speakers; however, some native English speakers and translators shared valuable insight on the specifics of the required communication skills. Besides, we conducted an hour-long discussion followed by a brainstorming session with five instructors who teach medical and health-related English to future mission participants.

The most typical communication situations were related to car accidents, MEDEVAC calls, taking a person to the hospital, and writing a report about the accident. In case of car accidents and injuries both as a result of explosions and in peace time, interaction with victims and other people involved in first aid and MEDEVAC call is necessary.

The participants described health problems experienced by themselves, their colleagues or the local population that require communication in English for medical assistance. The cases included hernia, broken arm, fever, nausea, malaria. A person who took members of his unit to a medical facility on several occasions participated as a mediator, taking care of the language interpretation part. He dealt with medical personnel from many different nationalities and had to explain symptoms, kind of pain, and medical recommendations. Apart from the above-mentioned cases, medical terminology or phases were necessary every time he went on a humanitarian mission, for health education, vaccination or medical assistance. During the interview, the need for peacekeepers in UN missions to be able to describe their own health problems to medical personnel in English was mentioned.

Participants from many countries confirmed that they had attended pre-deployment training on first aid and medical emergency. However, related English terminology was not studied enough due to insufficient time. In case of MEDEVAC, the participants were able to perform the procedure and identify necessary codes for the "nine liner," but hesitated to discuss the situation due to limited range of vocabulary. All of the interviewees agreed that abbreviations were difficult and not many people were familiar with them. A list of common abbreviations would be beneficial for the soldiers.

Finally, three main areas of vocabulary were identified for medical terminology support: parts of the body, injuries and other health issues (feelings, symptoms), and medical assets/devices used for first aid and healthcare prescriptions. 


\section{A framework for mobile language assistance}

Extensive literature review of mobile language learning experiments during the last decade demonstrated a wide spectrum of approaches, from SMS-based distribution of "a word of the day" for regular vocabulary extension to collaborative clarification of the meaning or game-based scenarios. Unfortunately, none of the strategies used in the experiments could be recommended “as is" for multinational partners' language assistance for the following reasons:

- in most cases participants were schoolchildren or students enrolled in some language course;

- $\quad$ the range of mobile devices was limited for the experiment;

- the participants share the same mother language;

- no individualization of language learning activities was offered.

Vocabulary learning and memorization strategies recommended by second language teachers, independently of their technological implementation, were also studied. However, not all recommendations promise to be efficient in our case, as the limited attention of the learner due to other tasks and priorities, as well as short and irregular intervals of time devoted to learning are not taken into account. However, many useful elements may be combined to address the individual learner's needs, specifics of adult learning, including self-control and cognitive support, multilingual and multicultural differences.

Taking into account the rapid changes in the availability and functionalities of mobile technologies, it is important to suggest a framework for sustainable cooperative development of mobile language assistance rather than focus on a single solution. The main goals are to ensure consistency and efficiency of learning content development, facilitate its longevity and reuse, and ensure its acceptance by the users. The framework consists of guidelines for creating learning content which could be selected by the end-users directly or aggregated and combined into sequences by the teachers. Based on the guidelines, some learning strategies for medical terminology learning were suggested:

- a structured dictionary of body parts, cross-referenced with injures, symptoms and actions;

- a sequenced video-clip collection supported by subtitles;

- $\quad$ an individual snapshot of a glossary allowing note-taking (translation).

The implementation of these strategies for mobile devices should take into account the fact that visual and audio information would be more appropriate than textual, and memorization mechanisms in a stressful environment need to be supported through 
dual-coding (visual-audio combinations), contextual placement, timely and meaningful repetitions, and learner engagement. As learning content might be used in information-noisy environment with external diverters of the learner's attention, it is supposed to be attractive, challenging, and motivating, and perceived rather as "edutainment” than a formal exercise.

\section{Conclusion}

Mobile technologies have made an important step in blurring the line between the author and the user of the content by easy capturing and publishing of photos, video, and audio fragments. Together with their communication potential still to unfold in the network environment, they might support immersive learning strategies, learning by doing supported by peers instead of formal learning, and assessment by a teacher.

An important impact of the social web on the community is manifested in the skills to create content, desire to share it, and practice to communicate and take advice from each other. With some organizational help, technological framework and good coordination, a significant amount of learning content may be created by multinational partners for common use.

\section{Acknowledgement}

This work was funded by the Coalition Warfare Program (CWP) as part of the Mobile Learning Environment (MoLE) Project and awarded by the Office of Naval Research Global (ONRG) under contract N62909-11-1-7045.

\section{Notes:}

1 Keith G. Stewart, H. Clarke, P. Goillau, N. Verrall and M. Widdowson, "Non-Technical Interoperability in Multinational Forces," paper presented at the 9th International Command and Control Research and Technology Symposium "The Power of Information Age Technologies," Copenhagen, September 2004.

2 Clark Quinn, "mLearning: Mobile, Wireless, In-Your-Pocket Learning," LiNE Zine (Fall 2000), <http://www.linezine.com/2.1/features/cqmmwiyp.htm> (30 Sep. 2011). 
3 John Traxler, "Defining mobile learning", paper presented at the IADIS International Conference on Mobile Learning, Qawra, Malta, 28-30 June 2005, 261-266, $<$ http://iadis.net/dl/final_uploads/200506C018.pdf $>$.

4 ADL Mobile Learning team, Mobile Learning Resources, 2011, $<$ http://adlmobile.wikispaces.com/> (20 December 2011).

${ }^{5}$ Garry Woodill, "The Evolution of the definition of mobile learning," Float Mobile Learning, 2011 <http://floatlearning.com/2011/08/the-evolution-of-the-definition-ofmobile-learning/> (30 Sep. 2011).

${ }^{6}$ Amit Carg, "The future of e-Learning is mobile," Upside Learning, 10 June 2010, $<$ http://www.upsidelearning.com/blog/index.php/2010/06/10/the-future-of-e-learning-ismobile-mlearncon/> (30 Sep. 2011).

7 Yiannis Laouris and Nikleia Eteokleous, "We need an educationally relevant definition of mobile learning," Proceedings of the 4th World Conference on Mobile Learning, Cape Town, South Africa, 25-28 October 2005, pp. 28-43.

Dr. KATERYNA SYNYTSYA is Deputy Director of the International Research and Training Centre for Information Technologies and Systems in Kiev, Ukraine.

GRETA KEREMIDCHIEVA is Director of the Language Training Department in Rakovski National Defence Academy in Sofia, Bulgaria.

E-mail: gkeremidchieva@yahoo.com.

They are both Deputy Chairs of the Advanced Distributed Learning Working Group of the PfP Consortium of Defense Academies and Security Studies Institutes. 